Supporting Information

\title{
Impact of Lipid Ratio on the Permeability of Mixed Phosphatidylcholine/Phosphatidyglycerol Membranes in the Presence of 1-Dodecyl-3- methylimidazolium Bromide Ionic Liquid
}

Sandeep Kumar ${ }^{\$}$, Markus Fischer ${ }^{\#}$, Navleen Kaur ${ }^{\S}$, Holger A. Scheidt ${ }^{\#}$,Venus Singh Mithu ${ }^{\$, *}$

${ }^{\$}$ Department of Chemistry, Guru Nanak Dev University, Amritsar 143005, India

'Institut für Medizinische Physik und Biophysik, Leipzig University, Leipzig 04109, Germany

AUTHOR INFORMATION

Corresponding Authors:

*venus.chem@gndu.ac.in 

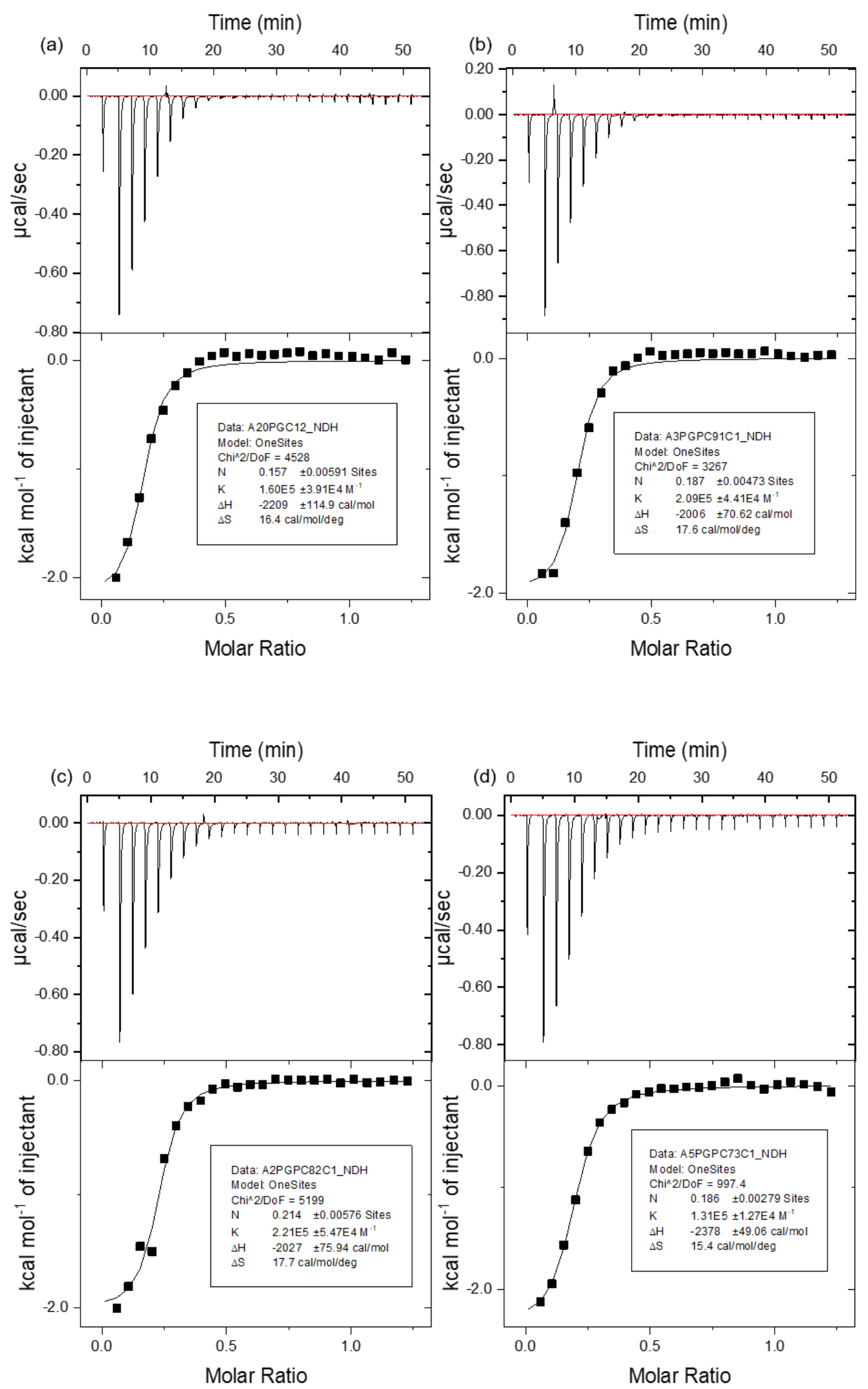

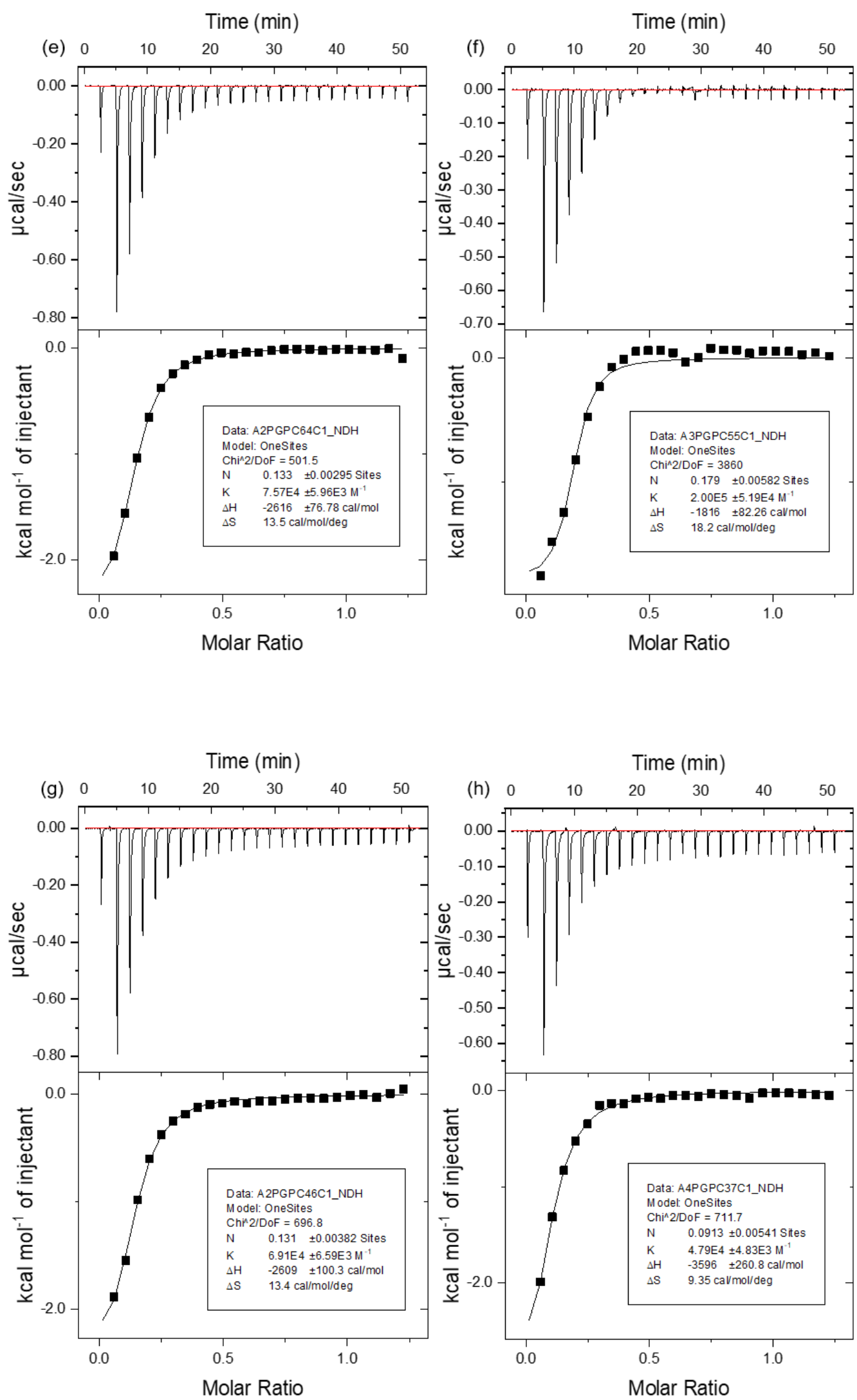

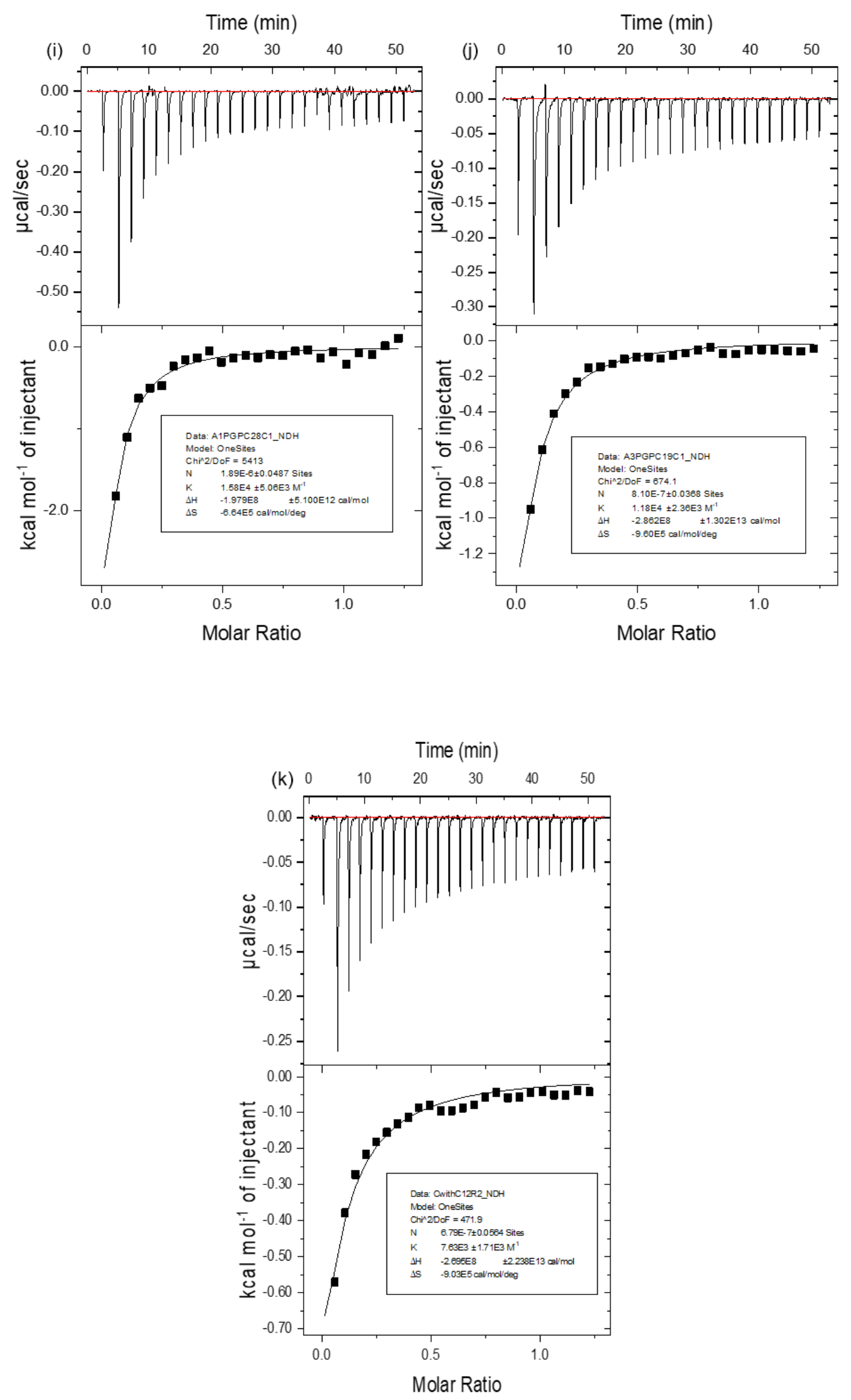
Figure S1. ITC thermogram and molar heat of binding obtained by titrating (a) PG:PC (10:0), (b) PG:PC (9:1), (c) PG:PC (8:2), (d) PG:PC (7:3), (e) PG:PC (6:4), (f) PG:PC (5:5), (g) PG:PC (4:6), (h) PG:PC (3:7), (i) PG:PC (2:8), (j) PG:PC (1:9), and (k) PG:PC (0:10) LUVs with $\left[\mathrm{C}_{12} \mathrm{MIM}\right]^{+} \mathrm{Br}^{-}$. 


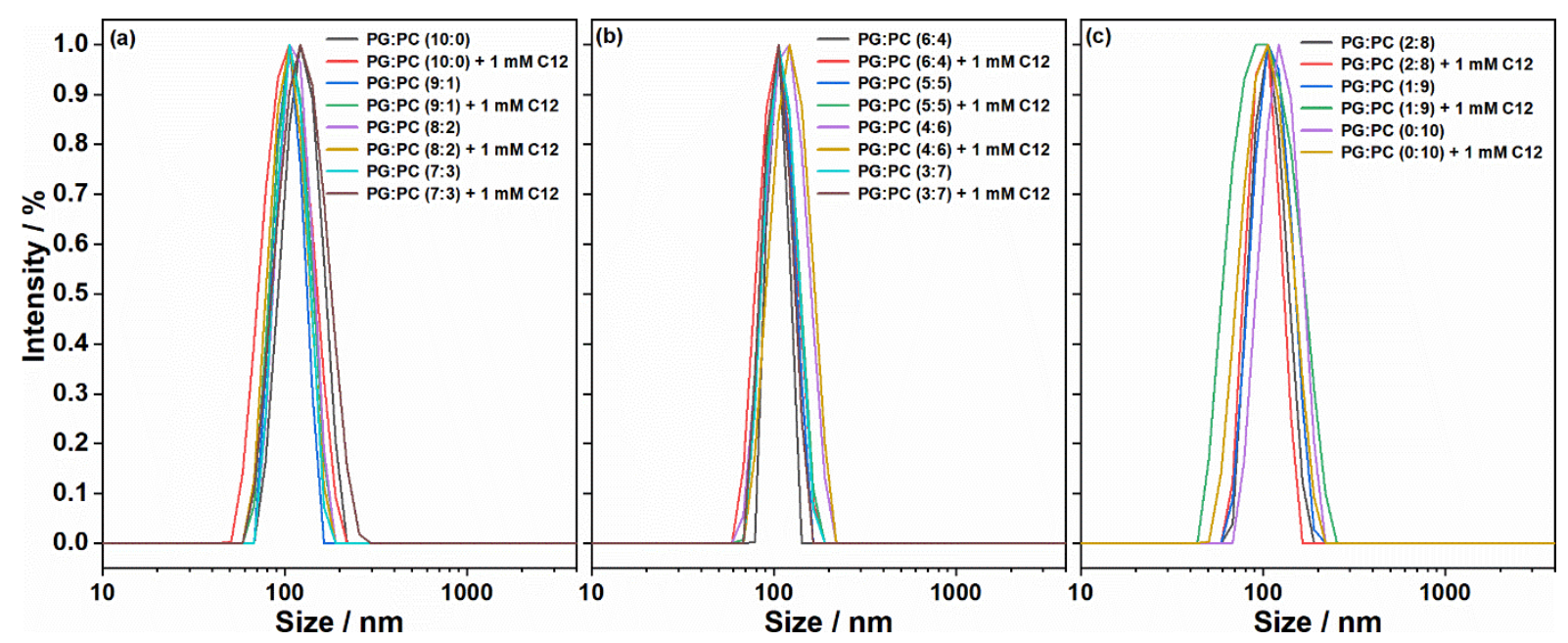

Figure S2. $D_{h}$ (hydrodynamic diameter) of (a) PG:PC (10:0), PG:PC (9:1), PG:PC (8:2), PG:PC (7:3), (b) PG:PC (6:4), PG:PC (5:5), PG:PC (4:6), PG:PC (3:7), and (c) PG:PC (2:8), PG:PC (1:9), PG:PC (0:10) LUVs in the function of $1 \mathrm{mM}\left[\mathrm{C}_{12} \mathrm{MIM}^{+} \mathrm{Br}^{-}\right.$at $25^{\circ} \mathrm{C}$. Size distribution data for PG:PC (10:0) and PG:PC (0:10) LUVs in the presence and absence of $\left[\mathrm{C}_{12} \mathrm{MIM}\right]^{+} \mathrm{Br}^{-}$ionic liquid are adapted with permission from [1]. Copyright 2018 American Chemical Society. 

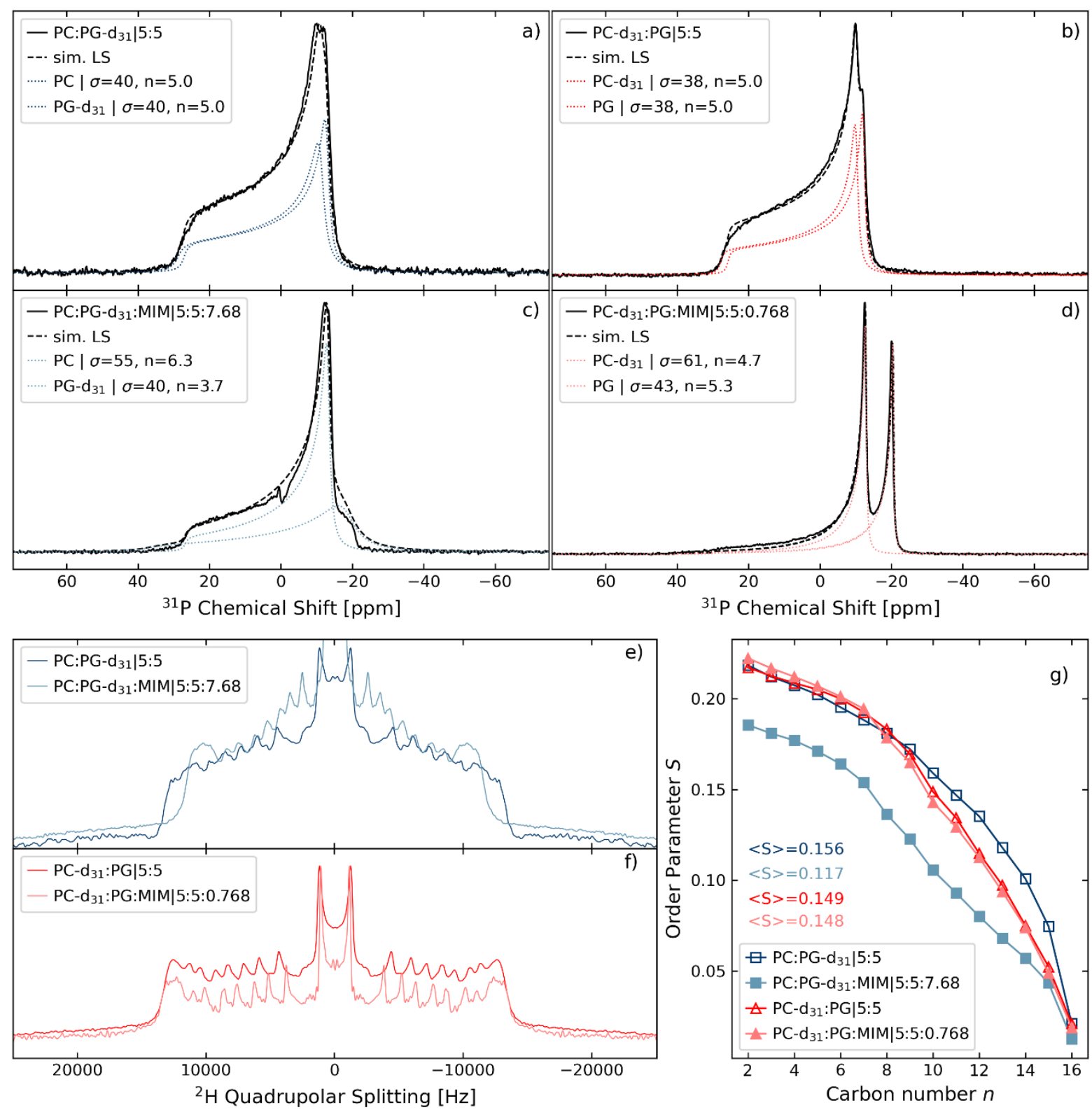

Figure S3. ${ }^{31} \mathrm{P}$ NMR spectra of PG:PC (5:5) in the (a, c) absence and $(b, d)$ presence of $\left[\mathrm{C}_{12} \mathrm{MIM}\right]^{+}$. The simulated lineshapes are superpositions of the PG:PC lamellar phases, (e, f) ${ }^{2} \mathrm{H}$ NMR spectra and (g) smoothed order parameter profiles of the PG:PC mixtures in the presence and absence of $\left[\mathrm{C}_{12} \mathrm{MIM}\right]^{+}$. 


\section{REFERENCES}

1. Kumar, S.; Scheidt, H.A.; Kaur, N.; Kaur, A.; Kang, T.S.; Huster, D.; Mithu, V.S., Amphiphilic Ionic Liquid-Induced Membrane Permeabilization: Binding Is Not Enough, $J$. Phys. Chem. B 2018, 122, 6763-6770. 